\title{
Article \\ Sustainable Crop Production, the Concurrent Adoption of Contract Farming, and Managing Risks through Income Diversification
}

\author{
Shoaib Akhtar ${ }^{1}$, Azhar Abbas ${ }^{2}$ (D), Hazem S. Kassem ${ }^{3,4}\left(\mathbb{D}\right.$, Salim Bagadeem ${ }^{5}$, Raza Ullah ${ }^{2}$ \\ and Bader Alhafi Alotaibi ${ }^{3, * \mathbb{C}}$
}

1 Centre of Excellence for Olive Research and Training (CEFORT), Barani Agricultural Research Institute, Chakwal 48800, Pakistan; Shoaibakhtar1799@gmail.com

2 Institute of Agricultural and Resource Economics, University of Agriculture, Faisalabad 38040, Pakistan; azhar.abbas@uaf.edu.pk (A.A.); raza.khalil@uaf.edu.pk (R.U.)

3 Department of Agricultural Extension and Rural Society, King Saud University, Riyadh 11451, Saudi Arabia; hskassem@ksu.edu.sa

4 Department of Agricultural Extension and Rural Society, Mansoura University, Mansoura 35516, Egypt

5 Faculty of Business Administration, Arab Open University, Riyadh 11681, Saudi Arabia; bagadeem@arabou.edu.sa

* Correspondence: balhafi@ksu.edu.sa; Tel.: +966-504240201

\section{check for}

updates

Citation: Akhtar, S.; Abbas, A.;

Kassem, H.S.; Bagadeem, S.; Ullah, R.;

Alotaibi, B.A. Sustainable Crop

Production, the Concurrent Adoption

of Contract Farming, and Managing

Risks through Income Diversification.

Agronomy 2021, 11, 973. https://

doi.org/10.3390/agronomy11050973

Academic Editors: Djamilia Skripnuk,

Gulnara Romashkina and

Berkeley Hill

Received: 19 March 2021

Accepted: 11 May 2021

Published: 13 May 2021

Publisher's Note: MDPI stays neutral with regard to jurisdictional claims in published maps and institutional affiliations.

Copyright: (c) 2021 by the authors. Licensee MDPI, Basel, Switzerland. This article is an open access article distributed under the terms and conditions of the Creative Commons Attribution (CC BY) license (https:/ / creativecommons.org/licenses/by/ $4.0 /)$.
Abstract: This paper is aimed at evaluating the factors affecting the concurrent adoption of two risk coping strategies among hybrid maize farmers, namely income diversification supplemented with offfarm work and contract farming in the wake of changing climatic conditions. Climatic changes and food insecurity at the national level have emerged as key risk elements for hybrid maize production due to varying economic conditions. The present paper addresses these risks by examining various sources of risks faced by hybrid maize farmers and develops ideas to tackle these risks. Bivariate and multinomial probit models were employed to analyze numerous factors that influence farmers' choice of the simultaneous adoption of income diversification (both on and off the farm) and contract farming at the farm level. The results reveal that hybrid maize farmers' socioeconomic attributes significantly affect their adoption of risk coping tools. Similarly, the climatic, economic (price-related), biological, and financial risk perceptions and risk preference significantly influence the utilization of risk coping strategies in maize production. These outcomes extend our understanding of farmers' risk preferences and provide parameters for policymakers to forestall diverse risk sources associated with hybrid maize production.

Keywords: maize farmers; risk management strategies; income diversification

\section{Introduction}

Globally, agricultural production is prone to several risks and uncertainties [1]. These risks and uncertainties are an integral part of agricultural operations around the globe and consequently lead to variability in production levels and farm incomes due to the varying nature of farm decisions taken under a particular set of climatic, economic, institutional, and social conditions [2]. These risks pose serious threats to agricultural production, mainly due to their potential to cause damage at the farm level [3]. The agriculture sector has a strong association with economic growth and the welfare of rural inhabitants, particularly in developing countries. Identification and mitigation of these uncertainties and risks in the agriculture sector are crucial [4] as they also affect other sectors of the economy. The higher prevalence of risks in agriculture is particularly caused by higher reliance on natural environmental conditions, i.e., rainfall, temperature variability, crop diseases, and pollution, as well as other risk sources including market shocks and price variability [5]. Hence, agricultural risks must be viewed from the farmers' perspective as a peril to the entire rural economy. 
Coping with uncertainty is critical as it affects the agricultural economy and allied segments such as agro-based industries and agribusinesses, mainly because of the presence of forward and backward linkages between the two [6]. Numerous management instruments exist to help farmers to avoid, transfer, share, spread, and/or take risks in various regions of the world [3,4]. The selection of a specific tool hinges upon individual circumstances and farmers' willingness to bear risks [7]. The literature points towards the existence of numerous tools and options for reducing risks, i.e., off-farm work, forward contracting, crop insurance, crop diversification, mixed farming, maintaining input reserves, and spreading out sales to cover price and market risks [8-12]. Farmers and managers may select a combination of risk coping tools for tackling variability in yield and price to reduce farm income variability [8]. However, several factors, including demographic attributes, access to credit and institutional services, and perceptions and preferences regarding risk, affect farmers' adoption of such tools [13].

As noted in [14], contract farming is one of the alternative options to stabilize farmers' income by offering assistance to small farmers in gaining early market access and reducing market price shocks. Although contractual terms may differ, the proportion of production that the contractor must purchase and the amount that has to be paid at a specific time are generally explicitly agreed upon and followed [15]. The significance of entering into contract agreements for the farming community is demonstrated in [16], where the authors observed that the risk is reduced to a minimal level when farmers switch to contract farming. In contract farming, the risk is mostly decreased by predetermined prices other than market price $[9,12]$. Proficiently planned and managed contract farming diminishes both the uncertainty and risk for beneficiaries in comparison to trading in an open market [17].

Income diversification and/or off-farm employment is another alternative to reduce farming households' income variability and risk. Specifically, off-farm earnings from non-agricultural work have been proven to decrease the risk associated with farm production [18]. The prime factors leading to the adoption of income diversification sources among farmers (both on the farm, such as growing different crops and mixing in other enterprises, and supplementing their livelihood through off-farm work) include, inter alia, a declining level of farm earnings and a dire need to provide security in the face of market risks and production uncertainty [19]. Off-farm income can be regarded as a way of diversification; however, the willingness of risk-averse farmers to work in stabilizing off-farm professions is higher than that of risk-loving farmers [20]. In this regard, the authors of [21] indicated that risk-averse farmers generally cultivate food crops along with focusing on a narrower range of farm activities. Furthermore, age, education, income level, family size, and credit access have been noted as significant determinants of farmers' risk attitudes [21].

As a global high-yielding cereal crop, maize is substantially important for developing countries with a rapidly increasing population that outstrips food supplies, such as Pakistan. Maize is also a high-value cash crop for the farmers of Punjab Province as it contributed $2.4 \%$ and $0.5 \%$ to value added in agriculture and gross domestic product (GDP), respectively, during the 2017-2018 cropping season. Maize has a number of different uses in Pakistan. Approximately $60 \%$ of the maize crop is used as poultry feed, $28 \%$ for wet milling, and $6 \%$ as a food item for human diets within the country [22]. Moreover, maize is a source of scarce foreign exchange and a raw material for the country's food industry [22]. Thus, due to such a high significance of maize to Pakistan's national economy and maize growers' income, there is a dire need for careful management and control of, inter alia, the production risks faced by maize crops at the farm level. Similar to other agricultural crops, hybrid maize also faces business and financial risks in Pakistan in particular and in the rest of the world in general [23]. Farmers can reduce the brunt of these risks through singular and concurrent adoption of risk management strategies.

Globally, numerous risk coping and management strategies have been used simultaneously by farmers [24-26]. However, few studies have been conducted on the simultaneous adoption of risk management strategies in Pakistan, and particularly on the concurrent adoption of contract farming and on/off-farm income diversification $[23,27]$. It is pertinent 
to note that the on-farm diversification and off-farm employment do not only stem from the increased exposure to risks among the farming community. There are many other reasons for adopting such options, including expertise diversity (skillset), human capital, economic motives (for instance, expected returns and investment quantum, market availability and its infrastructure, market demand, input prices, farmer-to-market intermediary linkages, etc.), logistics and infrastructure provision, research support, and information flow through the extension system [1-5,21]. However, the research premise of this study was limited to the adoption of such tools (income diversification and contract farming) for mitigating/coping with risks emanating from natural, biological, environmental, or economic/financial stimuli associated with the production of hybrid maize.

This study aimed to analyze the factors affecting the concurrent adoption of two risk coping strategies, namely diversification of income sources (both on- and off-farm) and contract farming, among hybrid maize farmers in Pakistan and to evaluate farmers' perceptions of disastrous risk sources and risk preferences. For this particular work, the reason for focusing on these two strategies stems from our discussions with field staff, key informants, and officials from the Agriculture Department of the Government of Punjab along with our own observations. At the time of pre-testing and focused group discussions (FGDs), the existence of these two strategies among hybrid maize growers was almost unanimously noted, and hence they were considered for empirical testing.

\section{Materials and Methods}

\subsection{Study Area}

For the present study, Punjab Province was selected as the study area (Figure 1). The province is the second largest in terms of area, the most populous, and the most agriculture-dominated province of the country. This province is situated in the semi-arid lowland region [28]. Punjab has 20.63 million hectares of geographical area, of which $59 \%$ is cultivated, while contributing about $53 \%$ to the overall agricultural GDP of the country. Moreover, about 74\% of Pakistan's entire cereal production comes from this province $[28,29]$. The motivation for selecting this area came from the fact that $81.3 \%$ of the total hybrid maize output of the country is contributed by Punjab as well as being the only producer of spring (hybrid) maize in the country [30]. (There are two growing seasons of maize in Pakistan, spring and autumn. The spring crop is sown from late February to the end of March, while the autumn crop is sown from the end of May to June.)

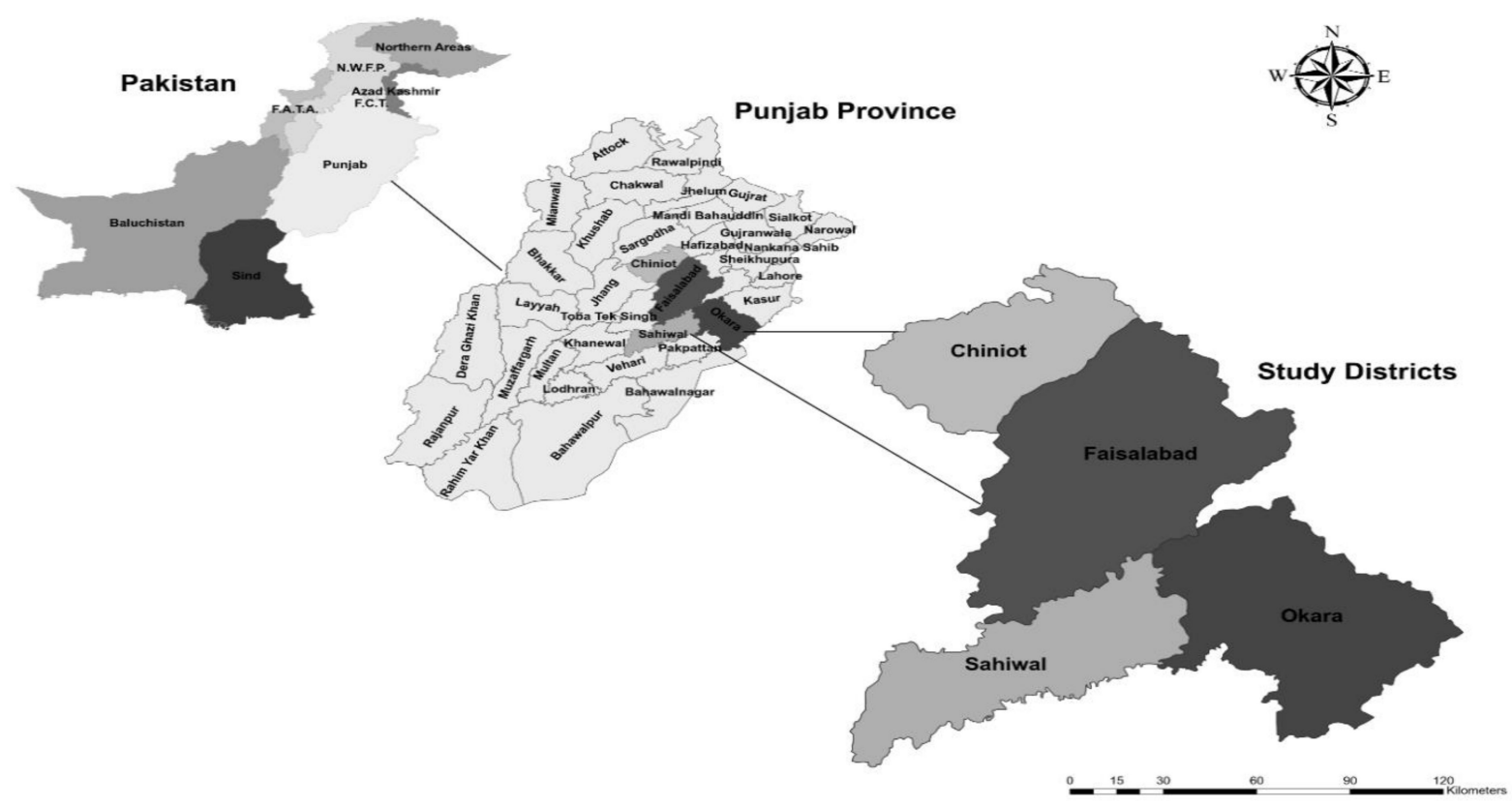

Figure 1. Map of study districts in Punjab Province, Pakistan. 


\subsection{Sampling}

Primary data were collected entirely from spring season hybrid maize growers between September and October 2016, through a well-structured questionnaire to explore the study objective. A multistage, stratified random sampling technique was used for sample selection, as shown in Figure 2. In the first stage, Punjab Province was selected as the main study area. In the second stage, four hybrid maize growing districts were selected, namely Faisalabad, Okara, Sahiwal, and Chiniot, while, in the third stage, two cities from each district were randomly selected. In the fourth stage, using stratified random sampling, two union councils were selected from each city according to their distances from the main markets and main road. In the fifth stage, villages were selected using a random sampling technique. Finally, farming households were selected from each selected village at random from the list of growers obtained from the Revenue Department of the Govt. of Punjab.

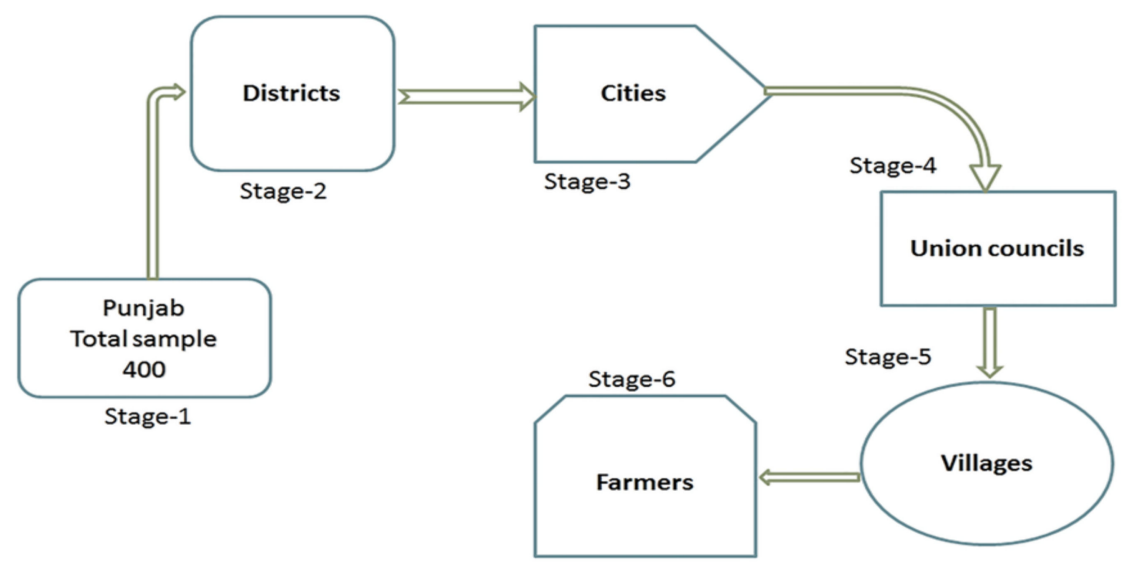

Figure 2. Sampling framework of the study.

Thus, 400 respondents (100 farmers per district) were selected from the study area using the Yamane sample size determination formula [31]. Data were collected through face-to-face interviews with the respondent farmers.

$$
n=\frac{N}{\left(1+N \cdot e^{2}\right)}
$$

where $\mathrm{n}$ is the total number of respondents, $\mathrm{N}$ is the overall number of selected farming households, and e is the error term, set at $\pm 15 \%(0.15)$.

\subsection{Instrument}

A questionnaire was used for field data collection. The questionnaire had three parts: socioeconomic attributes, such as age, education, extension contact, maize experience, farm size, main market distance, and districts; the adoption of risk management strategies; and farmers' risk perceptions and risk preferences along with the assembly of information on four likely risk management strategies used by hybrid maize producers. Before the final data collection, a pre-test of the designed questionnaire was conducted on 10 farmers; these questionnaires were excluded from the analysis.

Data on the uptake of contract farming among hybrid maize growers were recorded by directly asking them if they opted for such an intervention at their farm (equals 1 ) or not (0), as was done in the case of on-farm/off-farm income diversification. The specific question to elicit a response about income diversification read:

"Are you or any of your family members involved in working away from your farm in order to assure continuous/additional income in case any sort of risk or uncertainty of a price-related, biological, environmental, or financial nature is encountered? In a similar fashion, have you adopted multiple cropping and/or other farm enterprises (livestock, poultry, fishery, etc.) along with growing hybrid maize?" 
The answer to this question was also recorded as either 0 (no to both parts of the question) or 1 (yes to at least one part).

\section{Methodology}

The analytical framework used for this study comprises both bivariate probit and multinomial probit regressions to elicit factors that drive hybrid maize growers to mitigate various forms of risks through contract farming and/or income diversification. In essence, the bivariate probit method is aptly suited to modeling a dichotomous choice dependent variable under the random utility theory framework.

\subsection{Bivariate Probit Model}

The bivariate probit model serves the dual purpose of providing a correlation coefficient that shows the likelihood of a contemporaneous correlation between the decisions to adopt two risk management tools and estimates the effect of independent variables on the dichotomous dependent variable.

The concurrent adoption of on-farm income diversification sources supplemented with off-farm work and contract farming is used as a risk management strategy in hybrid maize production to offset the damage associated with various forms of risks. A bivariate probit model considering the possibility of a contemporaneous correlation in the decisions to adopt the two adaptation strategies can be specified as follows:

$$
Y_{i j}=x_{i j}^{\prime} \beta_{j}+\varepsilon_{i j}
$$

where $Y_{i j}(j=1, \ldots, m)$ represents the number of adaptation strategies considered in the present study, $x_{i j}^{\prime}$ is a $1 \times k$ vector of observed variables that affect the adaptation decisions, $\beta_{j}$ is a $k \times 1$ vector of unknown parameters (to be estimated), and $\varepsilon_{i j}$ is the unobserved error term. In this specification, each $Y_{j}$ is a binary variable, and thus Equation (2) is actually a system of $m$ equations ( $m=2$ in this case) to be estimated:

$$
\left.\begin{array}{l}
Y_{1}^{*}=\alpha_{1}+X \beta_{1}+\varepsilon_{1} \\
Y_{2}^{*}=\alpha_{2}+X \beta_{2}+\varepsilon_{2}
\end{array}\right\}
$$

where $Y_{1}^{*}$ and $Y_{2}^{*}$ are two latent variables underlying each of the adaptation strategy adoption decisions, such that $y_{j}=1$ if $y_{j}^{*}>0$ and 0 otherwise.

\subsection{Multinomial Probit Model}

An alternative estimation approach to the bivariate probit model is the use of a multinomial probit procedure where the choice set involves the possible combinations of risk management tools instead of just each risk management alternative alone. For the multinomial probit model, farmers can choose to adopt the following four combinations of management strategies, which are set as dependent variables:

i. Use no risk management strategy.

ii. Use contract farming only.

iii. Use income diversification only.

iv. Use income diversification and contract farming simultaneously.

Thus, the farmers may choose a mix of adaptation measures against various risk sources to exploit potential complementarities among available options [10,12]. Given this set of possible combinations, the multinomial model can be presented as follows:

$$
Y_{i m}=X_{i m} \beta_{m}+\varepsilon_{i m} \sim \operatorname{MVN}(0, \Sigma)
$$

Under this model, the farmers' decision is given by:

$$
Y_{i m}=1 \text { if } \beta_{m} x_{i m}+\varepsilon_{i m}>0
$$


while

$$
Y_{i m}=0 \text { if } \beta_{m} x_{i m}+\varepsilon_{i m} \leq 0
$$

where $Y_{i}$ indicates the combination of risk management strategies $\left(Y_{i}=1, \ldots, m\right)$ that the $i$ th farmer $(i=1, \ldots, n)$ selects, $X_{i}^{\prime}$ is a $1 \times k$ vector of independent variables that affect the risk management strategy combination selected by maize growers, $\beta$ is a $k \times 1$ vector of unknown parameters which are to be estimated, and $\varepsilon_{i}$ indicates the unobserved error term. Therefore, the unobserved error term is supposed to be a multivariate normal with 0 mean and variance-covariance matrix $\sum$, which is given by:

$$
\sum=\left[\begin{array}{ccc}
1 & \cdots & \rho_{1 M} \\
\vdots & \ddots & \vdots \\
\rho_{M 1} & \cdots & \rho_{M M}
\end{array}\right]
$$

\subsubsection{Independent Variables}

The socioeconomic features of farms and farming households included in the present study were age, education, number of contacts with extension workers, maize farming experience, maize farm size, main market distance from the farm gate, and the four hybrid maize growing districts (Faisalabad, Okara, Sahiwal, and Chiniot). Education is measured in number of schooling years, age is measured in years based on last birthday, and maize farming experience is measured in number of years growing maize. Household family size is the total number of family members living together. Farm size was measured as the sum of acres that a farming household manages. Main market distance was measured as the number of kilometers from the farm gate to the main market. Extension contact is 1 if the farmer has one or more contacts, and 0 otherwise. Regarding district dummies, Faisalabad is taken as the base outcome, whereas, for the other districts, 1 is set for Chiniot, Sahiwal, and Okara, respectively.

\subsubsection{Dependent Variable}

As explained above, the dependent variable used in the bivariate and multinomial probit models is the choice of using contract farming in hybrid maize production and/or on-farm/off-farm income diversification by the respondent farmers. In the case of the bivariate probit model, it takes the value of 1 or 0 , while, under the multinomial probit model, there are also discrete responses for each of the four types of strategies.

\subsubsection{Risk Perception}

Risk perception implies how growers in the study area perceive various sources of risk such as climatic, price-related, biological, and financial risks. Growers were asked to rate/score each risk source's severity and incidence on a five-point Likert scale ranging from 1 (very low) to 5 (very high) based on their understanding about these risks to identify how these risks affect their farm. Then, a risk factor is obtained by adding the consequence (c) and likelihood $(\mathrm{P})$ [32]. Using these risk factors, a risk matrix is obtained as outlined in [33,34] (Figure 3). This risk factor (RF) score is further classified into $2-5$ and 6-10, indicating "low" and "high" risks, respectively [32].

The variable connected with risk perception is binary in nature, i.e., 1 if growers considered a higher level of risk faced by hybrid maize and 0 otherwise (lower risk) based on the cumulative risk factor scores as shown in Figure 3. 


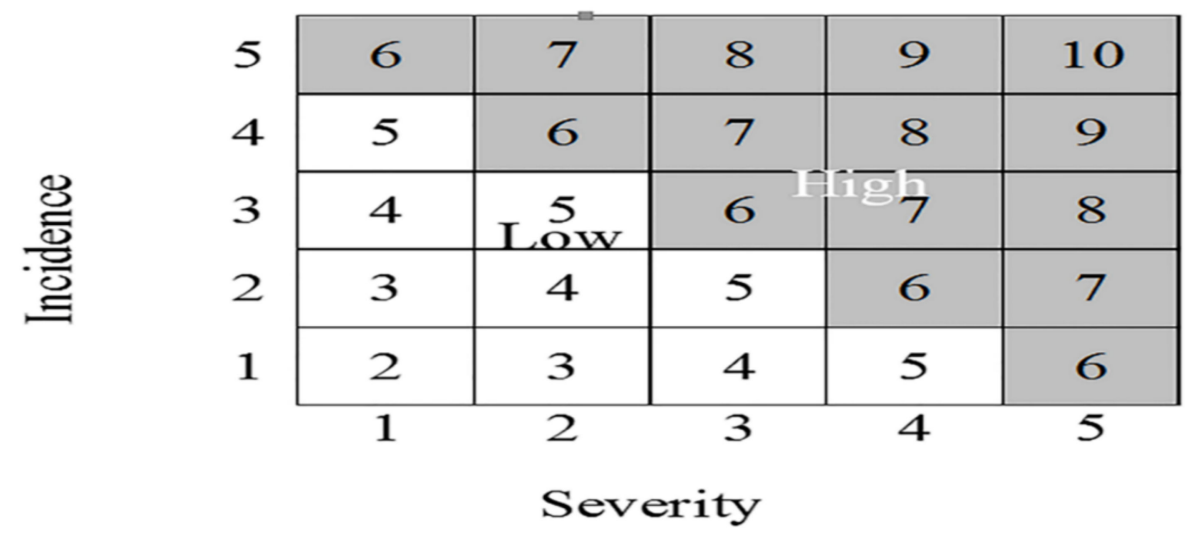

Figure 3. Risk matrix.

\subsubsection{Risk Preference}

The Equally Likely Certainty Equivalent (ELCE) model was applied to assess farmers' preferences regarding risks. The Certainty Equivalents (CEs) were obtained for an order of risky outcomes and were then matched with utility values [32]. For example, the farmers were asked to determine the monetary value of a specific outcome that makes them indifferent in a choice between two risky outcomes, namely total annual income (e.g., 80,000 PKR) and 0 PKR, with equal probabilities (in this example, the utilities related to 80,000 and 0 PKR are 1 and 0 , respectively). Suppose that the response is 41,000 PKR; this indicates the CE of the farmers with 80,000 PKR income level and 0 PKR with equivalent chances. Then, the farmers were inquired again to state the monetary value of a specific outcome that makes them indifferent between the two risky outcomes of 41,000 and 0 PKR with equal probabilities. This process continued until appropriate data points were found. A similar process was used for the other portion of income distribution to obtain the CEs and match them with the utility values. Farmers' response of 41,000 PKR is the CE for indeterminate payouts of 80,000 and 0 PKR with matching probabilities (each 0.5). Then, the utility values for this CE are as follows:

$$
U(41,000)=0.5 u(0)+0.5 u(80,000)=0.5(0)+0.5(1)=0.5
$$

After finding sufficient CEs and matching them to the utility values, a cubic utility function was applied to assess the utility of each farming household. The equation of the cubic utility function is as follows:

$$
U(w)=\alpha_{1}+\alpha_{2} w+\alpha_{3} w^{2}+\alpha_{4} w^{3}
$$

Risk aversion is associated with the cubic utility function, indifferent risk attitudes, and risk perceptions [35]. Although utility is frequently measured on an ordinary scale, this form of utility function can be transmuted into a numerical measure of risk aversion called absolute risk aversion [36-38]. The absolute risk aversion is given by:

$$
r_{a}(W)=-\frac{U^{\prime}(W)}{U^{\prime \prime}(W)}
$$

where $U^{\prime}$ and $U^{\prime \prime}$ are the first- and second-order derivatives of wealth $(W)$, respectively, and $r_{a}(W)$ is a parameter of absolute risk aversion. Income is used as a proxy for wealth, as reported in [39]. If the respondent is risk-averse, risk-loving, or risk-neutral, then the absolute risk aversion coefficient is positive, negative, or zero, respectively. Farmers' risk preference in the analysis is 1 if the respondent reflects a risk-averse attitude and 0 otherwise. 


\section{Results and Discussion}

\subsection{Descriptive Statistics}

Table 1 presents the summary statistics of the continuous and discrete variables used in this study. Approximately $78 \%$ of the hybrid maize growers indicated a riskaverse preference. They considered price, biological, and climate risks as major risk sources, whereas nearly $79 \%, 69 \%, 72 \%$, and $61 \%$ perceived price, climate, biological, and financial risks, respectively, as key risk sources for the hybrid maize crop. It is also evident from this table that more than $60 \%$ of the growers were cultivating hybrid maize under contract farming, either alone or in combination with on-farm/off-farm income diversification, while the percentage of growers only pursuing on/off-farm diversification stands at $49 \%$. Moreover, about $18 \%$ of hybrid maize growers do not pursue any risk management strategy from within the two options of contract farming and on-farm/offfarm income diversification. This is not astonishing in the given socioeconomic context of the study area, as a healthy proportion of farmers have been found in previous research to complain about any intervention to safeguard against a risky event $[40,41]$.

Table 1. Study variables and descriptive statistics.

\begin{tabular}{|c|c|c|c|}
\hline Variables & Mean & S.D. & Description \\
\hline \multicolumn{4}{|c|}{ Dependent Variables } \\
\hline \multicolumn{4}{|c|}{ Bivariate Probit Model } \\
\hline Contract farming (binary) & 0.61 & 0.49 & $\begin{array}{l}\text { Dummy takes the value } 1 \text { if contract } \\
\text { farming and } 0 \text { otherwise }\end{array}$ \\
\hline Income Diversification (binary) & 0.49 & 0.50 & $\begin{array}{l}\text { Dummy takes the value } 1 \text { if } \\
\text { diversification and } 0 \text { otherwise }\end{array}$ \\
\hline \multicolumn{4}{|c|}{ Multinomial Probit Model } \\
\hline No strategy (Base outcome) (binary) & 0.18 & 0.38 & $\begin{array}{c}\text { Dummy equals } 1 \text { if no strategy used and } \\
0 \text { otherwise }\end{array}$ \\
\hline Contract farming only (binary) & 0.34 & 0.47 & $\begin{array}{c}\text { Dummy equals } 1 \text { if only contract farming } \\
\text { and } 0 \text { otherwise }\end{array}$ \\
\hline Income diversification only (binary) & 0.21 & 0.41 & $\begin{array}{c}\text { Dummy equals } 1 \text { if only diversification } \\
\text { and } 0 \text { otherwise }\end{array}$ \\
\hline Both (ii) and (iii) simultaneously (binary) & 0.27 & 0.45 & $\begin{array}{l}\text { Dummy equals } 1 \text { if contract farming and } \\
\text { income diversification and } 0 \text { otherwise }\end{array}$ \\
\hline \multicolumn{4}{|c|}{ Explanatory Variables } \\
\hline \multicolumn{4}{|c|}{ Farmers' Characteristics } \\
\hline Age (years) & 44.77 & 9.93 & Continuous \\
\hline Education (years) & 6.89 & 4.02 & Continuous \\
\hline Extension contacts (binary) & 0.77 & 0.42 & $\begin{array}{l}\text { Dummy equals } 1 \text { if contact with } \\
\text { extension agent and } 0 \text { otherwise }\end{array}$ \\
\hline Maize experience (years) & 12.20 & 5.45 & Continuous \\
\hline Maize farm size (acres) $*$ & 33.32 & 33.93 & Continuous \\
\hline Family size (number) & 6.27 & 1.62 & Continuous \\
\hline Main market distance (Km) & 15.83 & 8.78 & Continuous \\
\hline Chiniot (district) & 0.25 & 0.43 & $\begin{array}{c}\text { Dummy equals } 1 \text { if the district is Chiniot } \\
\text { and } 0 \text { otherwise }\end{array}$ \\
\hline Okara (district) & 0.25 & 0.43 & $\begin{array}{c}\text { Dummy equals } 1 \text { if the district is Okara } \\
\text { and } 0 \text { otherwise }\end{array}$ \\
\hline Sahiwal (district) & 0.25 & 0.43 & $\begin{array}{c}\text { Dummy equals } 1 \text { if the district is Sahiwal } \\
\text { and } 0 \text { otherwise }\end{array}$ \\
\hline \multicolumn{4}{|c|}{ Risk Perceptions } \\
\hline Price risk (binary) & 0.79 & 0.41 & 1 if price RF is above $5 ; 0$ otherwise \\
\hline Climate risk (binary) & 0.69 & 0.46 & 1 if climate RF is above $5 ; 0$ otherwise \\
\hline Biological risk (binary) & 0.72 & 0.45 & 1 if biological RF is above $5 ; 0$ otherwise \\
\hline Financial risk (binary) & 0.61 & 0.49 & 1 if financial RF is above $5 ; 0$ otherwise \\
\hline \multicolumn{4}{|c|}{ Risk preference } \\
\hline Risk aversion (binary) & 0.78 & 0.42 & $\begin{array}{l}\text { Dummy equals } 1 \text { if the farmer is } \\
\text { risk-averse and } 0 \text { otherwise }\end{array}$ \\
\hline
\end{tabular}

* The average farm size in the study area was 43.04 acres, with the minimum being 3 acres and the maximum being 175 acres, with an SD of 42.22 . Moreover, maize area as a percentage of total farm area was $75.06 \%$. 
The maize growing experience is quite long among the studied farmers, at about 12 years. This shows that they have enough knowledge about the maize production dynamics and operations, such as input procurement, crop husbandry management, and market situation. The educational status seemed poor-although expected in the context of Pakistani rural socioeconomic set-up-which reflects the possibility of constrained access to services and information on their part. The maize area stands at about 33 acres. There are two observations about this finding: although there is a majority of small farmers in the country, due to the practice of leasing and renting of land, this area is justifiable. The other aspect is the costly nature of crop production and fast linkages with market channels, which are only possible if a farmer has an economically feasible crop area to attract contractors and use social relations emanating from a big land holding, either owned or rented. The distance from the main market was found to be about $15 \mathrm{~km}$, which is not too much for farmers cultivating, on average, 33 acres under maize.

The results in Table 2 point towards the concurrent or singular adoption of the two risk management strategies, viz., contract farming and on-farm/off-farm income diversification. As pointed out above, more than $80 \%$ of maize growers resort to one or both strategies in order to combat various forms of risks; however, the percentage of farmers opting only for on-farm/off-farm diversification is less than those opting for contractual arrangements only (around $21 \%$ vs. 33\%).

Table 2. Distribution of farmers adopting various combinations of risk management tools.

\begin{tabular}{ccc}
\hline Management Strategy & $\boldsymbol{n}$ & $\mathbf{\%}$ \\
\hline No strategy & 71 & 17.75 \\
Income diversification only & 85 & 21.25 \\
Contract farming only & 135 & 33.75 \\
Both & 109 & 27.25 \\
Total & 400 & 100 \\
\hline
\end{tabular}

Table 2 also illustrates the combination proportion of maize farmers adopting the four combinations of the risk management strategies. Each farmer selected one out of the four presented combinations as a risk management strategy. The table shows that only a minority $(17.75 \%)$ of the selected farmers did not select a risk management strategy due to certain reasons, whereas $25 \%$ adopted multiple strategies. Nevertheless, the most popular strategy in isolation is contractual agreements. This outcome is also reported in [12].

\subsection{Coefficient Estimation from Bivariate Probit Analysis}

Before going into the formal analysis, a multicollinearity check was performed for independent variables. For this purpose, variance inflation factor (VIF) was employed to test the multicollinearity among the independent variables. The highest value of VIF was reported for maize growing experience (4.58) followed by farmers' age (4.57), while the values for the rest of the variables were less than 2 , indicating that there is no problem of multicollinearity in the model.

Table 3 presents the parameter estimates of bivariate probit analysis for assessment and comparison. The signs and significance of the majority of the estimates from the probit regression are parallel. The likelihood ratio test of rho is significant and positive (0.5624), with a significant Wald Chi-squared value of 87.14. The findings of the bivariate probit analysis indicate that farmers' age positively impacts the choice of contract farming, whereas it negatively impacts on-farm/off-farm income diversification, although it has a statistically insignificant impact on the choice of the former or latter strategy. However, the signs do support our a priori expectation in the context of the study area. It is quite evident that farmers with older age would be less likely to go off-farm or experiment with non-traditional crops or livestock. The reason behind this may be the fact they are closer to their family and farm [41] while having less vigor and enthusiasm to work away from their belongings. 
Table 3. Results of bivariate probit model.

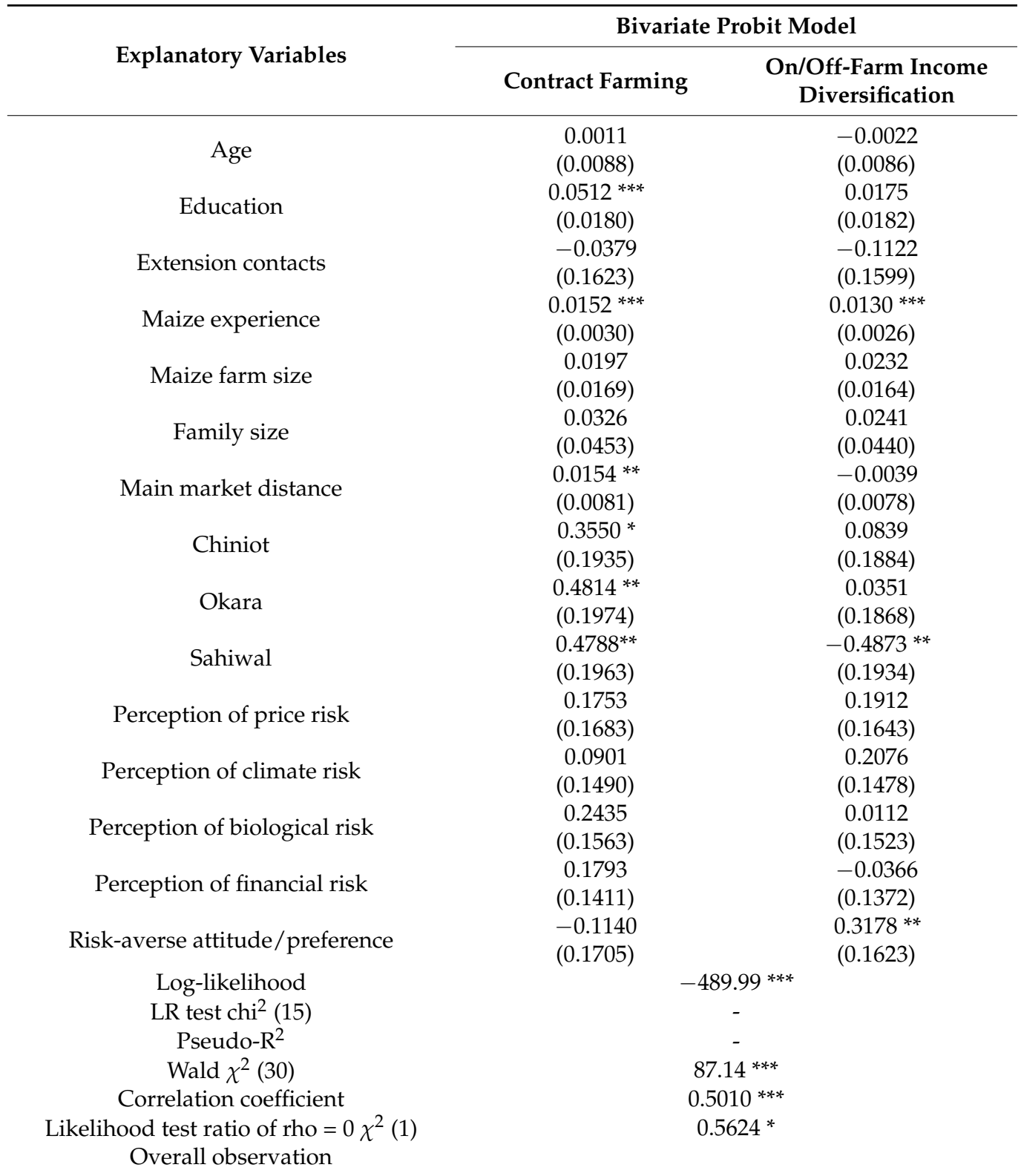

Figures in parentheses are standard errors. ${ }^{*}, * *$, and ${ }^{* * *}$ represent statistical significance levels at $10 \%, 5 \%$, and $1 \%$, respectively. Authors' own calculation from the survey data, September-November 2016.

Similarly, older farmers do develop sufficient linkages and repute, thus enabling them to find and enter into contract agreements [13,32]. Conversely, younger farmers, being energetic and having flexible time schedules, would be better placed to go off the farm to work and ensure an additional income stream in the wake of risky conditions. Therefore, older aged farmers may select less risky investments through contract arrangements [42,43]. Similarly, farming households' age positively impacts the growers' decision to choose one or a combination of the risk management tools [43-45].

The coefficient of years of schooling/education confirms the growers' selection of contract farming, through a statistically significant coefficient, implying a decisive role of this variable on the uptake of contract farming. It is clear from this result that farmers are more conversant about contractual arrangements if they are more educated and hence are more inclined towards its uptake to safeguard against various forms of risks. Some previous studies $[27,44,46]$ have indicated that years of schooling does positively impact the use of risk management strategies, particularly for contract farming. A somewhat different 
conclusion was drawn by the authors of [47], who revealed that growers' participation in contract farming negatively impacted their likelihood of choosing alternative mitigation strategies against risk. Nevertheless, an increased level of education is supposed to positively influence farmers' understanding of entering into a contractual mechanism. The more educated is a farmer, the higher is the probability of them being more familiar with contracting windows, having a better comprehension about contract conditions, and having a greater scope for the effective implementation of the set conditions thereafter. Our findings, however, show that there are many farmers who opt for a combination of mitigating options against any form of external/internal threat to farm production or farm-based earnings (see Table 2). Nearly $27 \%$ of the surveyed respondents reported the concurrent adoption of multiple strategies-contract farming and on/off-farm income diversification-in this particular study.

Similarly, findings reveal that farming/maize growing experience attracts contract farming as well as on/off-farm income diversification to counter risk outcomes for hybrid maize as both the coefficients are positive-as per our a priori expectation—and statistically significant. These findings provide a valid justification for the concurrent adoption of multiple strategies (two in the present case) to safeguard farmers against risky events/outcomes. These findings conform to the findings on a similar issue in [21,24]. This impact by farming experience (or experience in growing a particular crop) on choosing a specific set of options is relatively well-grounded. In this particular scenario, hybrid maize growers-having enough experience in its production as well as marketing-would find themselves better placed to go for a set of options instead of relying on a single one, casting a greater probability of adverse impacts through one or more (disastrous) events.

Contrary to our expectation, farmers who received technical advice from extension workers (proxied through the "contacts with extension staff") were less likely to participate in risk management strategies (both contract farming and on/off-farm income diversification). However, the authors of [47] supported this finding, noting that extension services negatively influence farmers' likelihood of participation in contract farming. Our findings further suggest that households with larger family size are positively influenced in the adoption of contract farming and on/off-farm income diversification due to their greater number of family members, indicating more labor force participation as well as a greater possibility of contacts to facilitate contract farming. Likewise, larger family size also helps in assuring household income maximization through the adoption of on/off-farm income diversification due to the presence of excess labor readily available to be engaged in extra on/off-farm work. These findings on family size, however, are statistically non-significant, although reflecting an a priori sign of the coefficient. The findings also show that there is positive but statistically non-significant relationship between maize cultivated area and the grower's choice of adopting the two risk mitigation options. This result is in line with the authors of [48], whereas it is inconsistent with the authors of [27], who stated that off-farm income diversification is negatively affected by farm size.

The findings further reveal that growers located far away from the main market readily adopt contract farming compared with those who are located near the city. However, the adoption of income diversification options is not influenced by how close the main market is to the farm. Both these findings make intuitive sense. The growers located remotely from the main market receive incentivizing signals, as do the contractors, to go for a contractual arrangement. The former is urged by this remoteness to avoid higher transportation and transaction costs in a less familiar main market (which is located far away) and its operations, leading to an added risk of final price for their commodities as well as shortening the period of farmer-led harvesting operation and transferring the onus of natural, climatic, and price-related risks to contracting vendors who buy their pre-harvest produce, thus ensuring a guaranteed price of the standing crop no matter how the market/price behaves at the harvest time.

Alternatively, contractors who have to earn their livelihoods-mainly by speculation and realizing the premium for risk taking in risky farm ventures-through involving 
themselves in contractual agreements with potential growers are in a better position to bargain with farmers who are relatively far away from the main market. This is because farmers near the market will have viable contacts within the market and hence would prefer to mainly sell in-person, being more conversant with the daily market operations, price volatility, and tools and times for better prices. A research implication, however, is to observe how contractors behave with respect to the spatial placement of farmers with respect to markets, while keeping in view the added transportation, visiting, and transaction costs for such units. Thus, the farther the market is to the farm, the greater are the chances of finding potential farmers to get involved in such a pre-harvest arrangement.

On the income diversification front, the relationship based on the sign of the coefficientalthough being statistically non-significant-implies that the probability of selecting income diversification decreases with increased distance of the farm from the main market. We expected a similar sign for the coefficient a priori. To the extent of the sign of the coefficient, the finding is intuitively clear. The farming households located farther away from the main market are likely to receive limited market-related information as well as less information about the inception and successfully running of allied on-farm activities including non-traditional crops and livestock. Finding and joining off-farm work would be further complicated due to increased job-search cost and the subsequent cost of commuting to and from the job to home $[41,44,46]$. An in-depth and sophisticated analysis in future research could provide further insights into such aspects as to why remote farmers find it difficult to pursue off-farm work.

However, economically speaking, the marginal product of rural/farm labor is very low, so growers would therefore be motivated to work off-farm to achieve higher marginal productivity per worker and hence increased wages. In a close and socially bound rural community such as in the study area, people prefer to avoid delays and hurdles to join their families even in minor family-based issues, as well as in more serious endeavors. Conversely, farmers in remote areas have limited access to the city and thus have less opportunities to meet with people and companies who can guide/offer them to work away from the farm. Similarly, the finding on contract farming vis-à-vis distance from market is further justified by the fact that it would require additional traveling and transportation costs on the part of farmers to monitor price movements within the market before final sale of the produce, thus avoiding such costs by forming a pre-harvest contract. In an alternative situation, they would need to bear additional transportation costs when the farm is sufficiently away from the main market/city. As a result, farmers in such areas are hesitant to monitor daily prices and then to decide to dispose of produce [45]. The results also indicate that farmers belonging to different hybrid maize-growing areas opt for the adoption of a risk management instrument in the form of contract farming at similar levels. In contrast, the probability of going for on/off-farm income diversification subsides significantly among the farmers belonging to Sahiwal district.

The covariates for such an outcome represent an additional empirical finding for researchers. Covariates on the perception of price, climate, and biological risks show expected a priori positive signs, although being non-significant statistically.

The findings further indicate that growers' risk-averse preference significantly and positively impacts their choice to adopt on-farm/off-farm income diversification, whereas it negatively but insignificantly impacts the choice of contract farming. These findings contradict some previous studies $[27,47]$. Farming risks emerging from price, biological, financial, and climate risk sources may lead to a crop disaster and potentially impact farmers' earnings. These risks threaten maize crop production through increased yield losses, which ultimately hinder growers from cultivating maize. Price, biological, climate, and financial risk perceptions (non-significantly but positively) impact farmers' decisions to choose contract farming, except financial risk which shows a negative sign on its coefficient. This result confirms the possibility of employing on/off-farm income diversification as a risk management tool. Thus, the probability of opting for on/off-farming income diver- 
sification is shown to be positively and significantly influenced by having a risk-averse preference among farmers.

\subsection{Coefficient Estimation from Multinomial Probit Analysis}

To estimate coefficients of the parameters linked with the uptake of one or more strategies separately or concurrently for the four categories of options in the present study, a multinomial probit model was estimated. The results of this analysis are presented in Table 4. As a default, no strategy was taken as the base (first) category for analysis. In contrast, the bivariate probit method yielded different estimates considering that an individual can adopt only one outcome among a set of collective alternatives. The major determinants that ensure the use of contract farming as a risk management strategy include years of schooling (education), maize farming experience, cultivated maize area, regional background (e.g., belonging to Okara district), and climate risk perception.

Table 4. Multinomial probit model estimates for on-farm/off-farm income diversification and contract farming.

\begin{tabular}{|c|c|c|c|}
\hline Independent Variables & Contract Farming & $\begin{array}{c}\text { Income } \\
\text { Diversification }\end{array}$ & $\begin{array}{l}\text { Income Diversification and } \\
\text { Contract Farming }\end{array}$ \\
\hline Age & $\begin{array}{l}-0.0077 \\
(0.0145)\end{array}$ & $\begin{array}{l}-0.0143 \\
(0.0157)\end{array}$ & $\begin{array}{l}-0.0002 \\
(0.0148)\end{array}$ \\
\hline \multirow{2}{*}{ Education } & $0.0632 * *$ & 0.0060 & 0.0387 \\
\hline & $(0.0308)$ & $(0.0319)$ & $(0.0308)$ \\
\hline \multirow{2}{*}{ Extension contacts } & -0.2535 & -0.3170 & -0.2266 \\
\hline & $(0.2853)$ & $(0.2878)$ & $(0.2854)$ \\
\hline \multirow{2}{*}{ Maize experience } & 0.0563 ** & $0.0643^{* *}$ & $0.0587^{* *}$ \\
\hline & $(0.0288)$ & $(0.0305)$ & $(0.0285)$ \\
\hline \multirow{2}{*}{ Maize farm size } & $0.0214^{* * *}$ & 0.0076 & 0.0035 \\
\hline & $(0.0048)$ & $(0.0061)$ & $(0.0051)$ \\
\hline \multirow{2}{*}{ Family members } & -0.0312 & -0.0874 & 0.0030 \\
\hline & $(0.0760)$ & $(0.0804)$ & $(0.0755)$ \\
\hline \multirow{2}{*}{ Main market distance } & 0.0163 & -0.0058 & 0.0146 \\
\hline & $(0.0136)$ & $(0.0144)$ & $(0.0137)$ \\
\hline \multirow{2}{*}{ Chiniot } & 0.1259 & -0.2340 & 0.4292 \\
\hline & $(0.3325)$ & $(0.3370)$ & $(0.3261)$ \\
\hline \multirow{2}{*}{ Okara } & $0.8157^{* *}$ & 0.2564 & $0.6202 *$ \\
\hline & $(0.3476)$ & $(0.3525)$ & $(0.3461)$ \\
\hline \multirow{2}{*}{ Sahiwal } & 0.4127 & $-0.7403^{* *}$ & -0.0428 \\
\hline & $(0.3233)$ & $(0.3416)$ & $(0.3242)$ \\
\hline \multirow{2}{*}{ Perception of price risk } & 0.1391 & 0.0743 & 0.4759 * \\
\hline & $(0.2803)$ & $(0.2883)$ & $(0.2908)$ \\
\hline \multirow{2}{*}{ Perception of climate risk } & 0.4052 * & $0.6088^{* *}$ & 0.3824 \\
\hline & $(0.2494)$ & $(0.2640)$ & $(0.2492)$ \\
\hline \multirow{2}{*}{ Perception of biological risk } & 0.1710 & -0.1031 & 0.3232 \\
\hline & $(0.2645)$ & $(0.2678)$ & $(0.2706)$ \\
\hline \multirow{2}{*}{ Perception of financial risk } & 0.1958 & -0.0414 & 0.1800 \\
\hline & $(0.2395)$ & $(0.2486)$ & $(0.2392)$ \\
\hline \multirow{2}{*}{ Risk aversion attitude/preference } & 0.0932 & $0.6149^{* *}$ & 0.2629 \\
\hline & $(0.2795)$ & $(0.3047)$ & $(0.2808)$ \\
\hline Log-likelihood & & $-480.78^{* * *}$ & \\
\hline Wald $\chi^{2}(45)$ & & 99.65 & \\
\hline Overall observation & & 400 & \\
\hline
\end{tabular}

Figures in parentheses are standard errors. ${ }^{*}, * *$, and ${ }^{* *}$ represent statistical significance levels at $10 \%, 5 \%$, and $1 \%$, respectively.

The positive and significant value of the coefficient of education suggests that, with more education, individuals are likely to adopt contractual arrangements to cater for risky outcomes related to market, price, and nature. In contrast, as shown in the bivariate model, education does not show a significant impact on the use of the on/off-farm income diversification strategy to adapt to climate change. This finding also implies that well-educated 
farmers would prefer to go for contract farming in the study area than to diversify (on/offfarm). As hybrid maize production has a well-established market and production potential, people with more education would be less willing to try other types of crops and/or enterprise mix. Hybrid maize being well-suited to the local agro-climatic conditions attracts farmers to continue growing this crop while at the same time insuring against price and climatic risks by moving towards pre-harvest contract agreements. This finding is further supported by the researchers' observation about the relatively weaker popularity of income diversification drives among hybrid maize growers, as only about $21 \%$ adopt this strategy as the only option (although about $48 \%$ farmers practice it either separately or combined with contract farming), while contract farming is popular among approximately $60 \%$ of hybrid maize growers (Table 2). The reason as quoted by some of the respondents for not opting for income diversification is the possibility of an increased level of price uncertainty linked with each additional crop as well as the varying nature of crop/enterprise-specific risks.

Another significant determinant in the uptake of contract farming and income diversification is perception of climate risk. This variable showed a statistically non-significant impact on both these options under the bivariate model. However, we see some support for this finding under the multivariate probit model. The authors of $[43,44]$ noted a similar impact of climate risk perception on the uptake of singular or multiple options to mitigate climate risks. As revealed by the bivariate probit results as well, hybrid maize farmers' risk-averse preference determines the adoption of on/off-farm income diversification, whereas contract farming or a combined strategy of both options is least influenced by such preferences. In addition to the risk-averse preference, most of the investigated determinants also interpret the adoption of contract farming in the bivariate model. However, in the multinomial probit approach, parameter estimates on age and family size exhibit negative signs in contrast to the bivariate model where they have positive signs. Nevertheless, their impact on the choice of both options individually or combined is statistically non-significant.

Similarly, there is a significant determinant of the adoption of on/off-farm diversification with respect to Sahiwal district. The effect of most of the factors identified in the bivariate probit model generally corroborate the multinomial probit model.

The determinants that interpret the use of the combination of on/off-farm income diversification and contract farming include maize farming experience, Okara district, and price risk perception. These results show that the role of many factors in the concurrent adoption of multiple strategies weakens compared with the role of factors in the case of an individual strategy in bivariate settings. The high values of Wald statistics and log-likelihood show a high level of explanatory power of the independent variables.

\section{Conclusions and Implications}

The current study reveals that most hybrid maize growers have a risk-averse preference and are hesitant toward risk taking. Such a preference is one of the critical factors that influence farmers' hybrid maize crop cultivation through contract farming. Nevertheless, use of on/off-farm income diversification ranks second in the use of risk mitigation measures. Moreover, the majority of the growers ranked price, climate, and biological risks as high risk sources, whereas financial risk was ranked as a low risk source for the hybrid maize crop. The findings further show that more than $60 \%$ of the growers employ contract farming, whereas less than $50 \%$ of farming households adopted on/off-farm income diversification for dealing with risks associated with hybrid maize cultivation. About $27 \%$ of hybrid maize farmers use a combination of risk mitigation options; however, complementarity between the two choices is unclear as to whether contract arrangements entice farmers to diversify or not and vice versa. This is a classical case for further empirical investigation by the scientific community.

However, this study sheds light on the covariates of selecting single and combined strategies to insure against various forms of risks faced by the farming community. In this regard, the area under maize crop, farmers belonging to Okara district, and the perception 
of price risk were the prominent factors in the uptake of the combined strategy. This is intuitively clear in that people having more arable land will be devoting a larger area to hybrid maize while being better placed to diversify either in terms of multiple crops and/or farm enterprises on the farm, with unclear evidence on the uptake of off-farm livelihood generation. Similarly, education has been shown to have a positive role in the uptake of contract farming, thereby implying the significance of investing more in improving general as well as technical education. In addition, there should be a focus on creating awareness related to the contractual mechanism as well as its streamlining, particularly in Chiniot, Okara, and Sahiwal districts where many farmers resort to contractual arrangements. There is, however, a greater impetus required to train members of farming families and equip them with technical and vocational skills enabling them to earn a better livelihood when going for off-farm work, especially in Southern Punjab such as in Sahiwal. This will ultimately improve per capita earning in rural areas, leading to poverty reduction, weakened income inequality, and improved food security and living standards. Such a move is destined to benefit the farming sector in return as the farming families will have enough resources for timely sourcing of key inputs such as fertilizer, improved seed, timely tilling and harvesting, and allied operations, which then will enhance productivity per unit area.

Furthermore, the study findings obtained through bivariate and multinomial probit models can offer guidance on the adoption of risk management tools by providing detailed explanations, corollaries, and evidence that may further improve the understanding of growers' risk management choices. Some of the prominent set of covariates that lead to the adoption of contract farming and income diversification as separate strategies include maize farming experience and belonging to Sahiwal district; however, the perception about price risk-inherent to most domestic markets of the country in general and Punjab Province in particular-along with belonging to Okara district shape the decision to opt for a combined strategy. The implication of this finding is linked with the faster pace of industrialization as well as the focus on vegetable growth within this district. In essence, therefore, there is a need to provide farmers of other districts with up-to-date information regarding hybrid maize production such as possible price spread, area cultivated during the current season, and the potential markets where the produce can fetch a suitable price. The study findings can also assist extension institutions in modifying farmers' preferences regarding risk to encourage the adoption of risk management strategies.

This study can also aid future researchers in identifying various risk sources linked to agricultural crops and hybrid maize crops, relevant to the prevalence and similar severity of specific and concerned risk sources. Another avenue for future research lies in looking into farmers' risk management attitudes (extent and issues) in relation to various categories of farm size as economies of scale might force specific farmers to adopt or shun a particular set of risk coping strategies. In addition, the work could be further extended to evaluate factors and the extent of management options against a particular set of risk sources by taking into account farmers of various farm sizes, i.e., small, medium, and large. On the policy front, legislative work is required to streamline the contractual mechanism in the farming sector through devising protocols, limits, and compensation (for contractors if there is total failure of the crop) in order to benefit both parties.

Author Contributions: Conceptualization, S.A. and A.A.; Data curation, S.A. and A.A.; Formal analysis, S.A. and R.U.; Investigation, S.A. and S.B.; Methodology: R.U. and S.B.; Project administration, S.A.; Resources, B.A.A.; Supervision, A.A.; Validation, H.S.K.; Suggestions, H.S.K; Writing—original draft, S.A.; Writing-review and editing, B.A.A. All authors have read and agreed to the published version of the manuscript.

Funding: This research was funded by the Deanship of Scientific Research and RSSU at the King Saud University, Saudi Arabia, through the Research Group No. RGP-1441-511.

Institutional Review Board Statement: Ethical review and approval were waived for this study, due to the nature of information (insensitive) being sought from the respondents. However, all the 
relevant ethical guidelines under Helsinki Declaration were given due consideration and followed where applicable.

Informed Consent Statement: Informed consent was obtained from all subjects involved in the study.

Data Availability Statement: The data supporting reported results can be provided upon request to the interested individuals/researchers.

Acknowledgments: The authors are grateful to the Deanship of Scientific Research and RSSU at King Saud University for their technical support.

Conflicts of Interest: The authors report no conflict of interest.

\section{References}

1. Moschini, G.; Hennessy, D.A. Uncertainty, Risk Aversion, and Risk Management for Agricultural Producers. In Handbook of Agricultural Economics, 1st ed.; Gardener, B., Rausser, G., Eds.; North Holland: Amsterdam, The Netherlands, 2001; Volume 1A, pp. 87-153.

2. Mishra, A.K.; El-Osta, H.S.; Sandretto, C.L. Factors affecting farm enterprise diversification. Agric. Financ. Rev. 2004, 64, 151-166. [CrossRef]

3. Drollette, S.A. Managing Production Risk in Agriculture; AG/ECON/2009-03RM; Department of Applied Economics Utah State University: Logan, UT, USA, 2009.

4. Ullah, R.; Shivakoti, G.P.; Zulfiqar, F.; Karmran, M.A. Farm risks and uncertainties: Sources, impacts and management. Outlook Agric. 2016, 45, 199-205. [CrossRef]

5. Kurukulasuriya, P.; Rosenthal, S. Climate Change and Agriculture: A Review of Impacts and Adaptations; Environment Department Papers, No. 91.; Climate Change Series; World Bank: Washington, DC, USA, 2013.

6. Kammar, S.K.; Bhagat, R. Constraints experienced by farmers in adopting risk and uncertainty management strategies in rainfed agriculture. Pusa AgriSci. 2009, 32, 70-74.

7. Singh, G. Crop Insurance in India; IIMA Working Paper WP2010-06-01; Indian Institute of Management Ahmedabad: Ahmadabad, India, 2010.

8. Schaffnit-Chatterjee, C.; Kahn, B. Mitigating Climate Change through Agriculture; Deutsche Bank Research: Frankfurt am Main, Germany, 2011.

9. Ahsan, D.A. Farmers' motivations, risk perceptions and risk management strategies in a developing economy: Bangladesh experience. J. Risk Res. 2011, 14, 325-349. [CrossRef]

10. Abid, M.; Schilling, J.; Scheffran, J.; Zulfiqar, F. Climate change vulnerability, adaptation and risk perceptions at farm level in Punjab, Pakistan. Sci. Total Environ. 2016, 547, 447-460. [CrossRef]

11. Rizwan, M.; Qing, P.; Saboor, A.; Iqbal, M.A.; Nazir, A. Production risk and competency among categorized rice peasants: Cross-sectional evidence from an emerging country. Sustainability 2020, 12, 3770. [CrossRef]

12. Iqbal, M.A.; Abbas, A.; Naqvi, S.A.A.; Rizwan, M.; Samie, A.; Ahmed, U.I. Drivers of farm households' perceived risk sources and factors affecting uptake of mitigation strategies in Punjab Pakistan: Implications for sustainable agriculture. Sustainability 2020, 12, 9895. [CrossRef]

13. Akhtar, S.; Gu-cheng, L.; Ullah, R.; Nazir, A.; Iqbal, M.A.; Raza, M.H.; Iqbal, N.; Faisal, M. Factors influencing hybrid maize farmers' risk attitudes and their perceptions in Punjab Province, Pakistan. J. Integ. Agric. 2018, 17, 1454-1462. [CrossRef]

14. Sriboonchitta, S.; Wiboonpoongse, A. Overview of Contract Farming in Thailand: Lessons Learned; ADB Institute Discussion paper No. 112; Asian Development Bank Institute: Tokyo, Japan, 2008.

15. Baumann, P. Equity and Efficiency in Contract Farming Schemes: The Experience of Agricultural Tree Crops; Overseas Development Institute: London, UK, 2000.

16. Covey, T.D. Analysis of the Rough Rice Futures Contract; Agricultural economics research report/Mississippi Agricultural and Forestry Experiment Station, Mississippi State University: Mississippi State, MS, USA, 1985.

17. Li, Y.; Du, Z.-P. Agri-Food Supply Chain Network Robustness Research Based on Complex Network. In Proceedings of the 6th International Asia Conference on Industrial Engineering and Management Innovation, Tianjin, China; Qi, E., Ed.; Atlantis Press: Paris, France, 2016; pp. 929-938.

18. De Brauw, A.; Eozenou, P. Measuring risk attitudes among Mozambican farmers. J. Dev. Econ. 2014, 111, 61-74. [CrossRef]

19. Mangisoni, J.H.; Katengeza, S.; Langyintuo, A.; La Rovere, R.; Mwangi, W.M. Characterization of Maize Producing Households in Balaka and Mangochi Districts in Malawi; CIMMYT, Country Report-Malawi; International Maize and Wheat Improvement Center (CIMMYT): Nairobi, Kenya, 2011.

20. Timothy, A.J. Analysis of Risks and Mitigating Strategies amongst Poultry Farmers in Kaduna Metropolis. M.Sc. Thesis, Ahmadu Bello University, Zaria, Nigeria, 2015.

21. Poon, K.; Weersink, A. Factors affecting variability in farm and off-farm income. Agric. Fin. Rev. 2011, 71, 379-397. [CrossRef]

22. Government of Pakistan. Economic Survey of Pakistan 2017-2018; Ministry of Finance, Government of Pakistan: Islamabad, Pakistan, 2018. 
23. Akhtar, S.; Li, G.; Nazir, A.; Razzaq, A.; Ullah, R.; Faisal, M.; Naseer, M.A.R.; Raza, M.H. Maize production under risk: The concurrent adoption of off-farm income diversification and agricultural credit to manage risk. J. Integ. Agri. 2018, 18, 460-470. [CrossRef]

24. Zulfiqar, F.; Ullah, R.; Abid, M.; Hussain, A. Cotton production under risk: A simultaneous adoption of risk coping tools. Nat. Hazards 2016, 84, 959-974. [CrossRef]

25. Velandia, M.; Rejesus, R.M.; Knight, T.O.; Sherrick, B.J. Factors affecting farmers' utilization of agricultural risk management tools: The case of crop insurance, forward contracting, and spreading sales. J. Agric. Appl. Econ. 2009, 41, 107-123. [CrossRef]

26. Kouamé, E.B.-H. Risk, Risk Aversion and Choice of Risk Management Strategies by Cocoa Farmers in Western Côte D'ivoire. 2010. University of Cocody-AERC Collaborative PHD Program. Available online: https:/ / citeseerx.ist.psu.edu/viewdoc/download? doi=10.1.1.192.5506\&rep=rep1\&type $=$ pdf (accessed on 20 January 2021).

27. Lu, W.; Latif, A.; Ullah, R. Simultaneous adoption of contract farming and off-farm diversification for managing agricultural risks: The case of flue-cured Virginia tobacco in Pakistan. Nat. Hazards 2017, 86, 1347-1361. [CrossRef]

28. Abid, M.; Scheffran, J.; Schneider, U.A.; Ashfaq, M. Farmers' perceptions of and adaptation strategies to climate change and their determinants: The case of Punjab province, Pakistan. Earth Syst. Dyn. 2015, 6, 225-243. [CrossRef]

29. Badar, H.; Ghafoor, A.; Adil, S.A. Factors affecting agricultural production of Punjab (Pakistan). Pak. J. Agric. Sci. 2007, 44, 506-510.

30. GoP. Punjab Development Statisitics; Government of Punjab: Lahore, Pakistan, 2018.

31. Yamane, T. Problems to Accompany Statistics: An Introductary Analysis, 3rd ed.; Harper \& Row: New York, NY, USA, 1973.

32. Ullah, R.; Shivakoti, G.P. Adoption of on-farm and off-farm diversification to manage agricultural risks: Are these decisions correlated? Outlook Agric. 2014, 43, 265-271. [CrossRef]

33. Cooper, D.F.; Grey, S.; Raymond, G.; Walker, P. Project Risk Management Guidelines: Managing Risk in Large Projects and Complex Procurements, 1st ed.; John Wiley \& Sons: New York, NY, USA, 2005.

34. Rosenberg, L.; Hammer, T.; Gallo, A. Continuous Risk Management at NASA; NASA: San Jose, CA, USA, 1999.

35. Binici, T.; Koç, A.A.; Zulauf, C.R.; Bayaner, A. Risk attitudes of farmers in terms of risk aversion: A case study of lower Seyhan plain farmers in Adana province, Turkey. Turk. J. Agric. For. 2003, 27, 305-312.

36. Arrow, K.J. The role of securities in the optimal allocation of risk-bearing. Rev. Econ. Stud. 1964, 31, 91-96. [CrossRef]

37. Pratt, J.W. Risk aversion in the small and in the large. Econometrica 1964, 32, 122-136. [CrossRef]

38. Raskin, R.; Cochran, M.J. Interpretations and transformations of scale for the Pratt-Arrow absolute risk aversion coefficient: Implications for generalized stochastic dominance. West. J Agric. Econ. 1986, 11, 204-210.

39. Olarinde, L.; Manyong, V.M.; Akintola, J.O. Attitudes towards risk among maize farmers in the dry savanna zone of Nigeria: Some prospective policies for improving food production. Afr. J. Agric. Res. 2007, 2, 399-408.

40. Mishra, A.K.; Goodwin, B. Farm Income Variability and the Supply of Off-Farm Labor. Am. J. Agric. Econ. 1997, 79, 880-887. [CrossRef]

41. Ahmadzai, A. How is Off-farm Income Linked to On-farm Diversification? Evidence from Afghanistan. Stud. Agric. Econ. 2020, $122,1-12$.

42. Cahyadi, E.R.; Waibel, H. Is contract farming in the Indonesian oil palm industry pro-poor? J. Southeast Asian Econ. 2013, 30, 62-76. [CrossRef]

43. Deressa, T.T.; Ringler, C.; Hassan, R.M. Factors Affecting the Choices of Coping Strategies for Climate Extremes: The Case of Farmers in the Nile Basin of Ethiopia; IFPRI Discussion Paper 01032; International Food Policy Research Institute: Washington, DC, USA, 2010.

44. Ping, Q.; Iqbal, M.A.; Abid, M.; Ahmed, U.I.; Nazir, A.; Rehman, A. Adoption of off-farm diversification income sources in managing agricultural risks among cotton farmers in Punjab Pakistan. J. Appl. Environ. Biol. Sci. 2016, 6, 47-53.

45. Sibhatu, K.T.; Krishna, V.V.; Qaim, M. Production diversity and dietary diversity in smallholder farm households. Proc. Natl. Acad. Sci. USA 2015, 112, 10657-10662. [CrossRef] [PubMed]

46. Ashraf, M.; Routray, J.K.; Saeed, M. Determinants of farmers' choice of coping and adaptation measures to the drought hazard in Northwest Balochistan, Pakistan. Nat. Hazards 2014, 73, 1451-1473. [CrossRef]

47. Wainaina, P.W.; Okello, J.J.; Nzuma, J. Impact of contract farming on smallholder poultry farmers' income in Kenya. In Proceedings of the International Association of Agricultural Economists (IAAE) Triennial Conference, Foz do Iguaçu, Brazil, 18-24 August 2012.

48. Fawole, P.; Thomas, K. Effects of contract farming scheme on cassava production enterprise in Oyo state, Nigeria. J. Rural Econ. Dev. 2011, 20, 1-7. 